pulse-time modulated multiplex telephony has also been worked out, in which the valve is used as a cyclic switch and modulator or demodulator simultaneously.

Detailed reports of the investigations are in preparation.

\section{INDEXING PRACTICE: TRENDS IN GERMAN, AMERICAN AND BRITISH CHEMICAL SOCIETIES' PRACTICE}

\author{
By R. BRIGHTMAN
}

Imperial Chemical Industries, Ltd., Manchester

$\mathrm{M}^{2}$ OST organic chemists have found in literature searches that the tracing of entries relating to particular compounds may be difficult because of inconsistencies in indexing practice. For example, although in the introduction to the Collective Index 1923-32 to British Chemical Abstracts there is given a list of substituents such as amino-, chloro-, nitro-, etc., which in the Index are placed immediately after the remainder of the name, whether or not the substituent group is preceded by di-, tri-, etc., and although the name of the individual compound commences with that substituent, previous practice had varied. In earlier volumes "Nitrotoluene", for example, may be found under "Toluene, nitro-", "Nitrotoluene" or "Paranitrotoluene", with or without appropriate cross-references. Again, in one volume, "Nitrochloronaphthalene" appears as well as "Naphthalene-, nitrochloro", but "Tetranitronaphthol, $\alpha-$ ", is given only under " $T$ ", whereas "Trichloroacetic acid" appears under "Acetic acid, trichlor.". Disregarding variations in spelling, "paranitroaniline" is indexed under " $P$ " (Paranitroaniline), under "A" (Aniline, p-nitro-) and under "N" (Nitroaniline, p-), and the nitrotoluidines under "Aminotoluene, nitro", under "Nitro-toluidines", under "Toluene, nitroamino" and under "Toluidines, -nitro".

It is not surprising that consistency in indexing should grow slowly; and the present time may even be one of maximum confusion, due to the continual increase of potential morasses through the expansion of technical chemistry, as a comparison of college text-books of organic chemistry of the last thirty to forty years will illustrate. None the less, the present inconsistencies imply that, to be sure of finding all references to a chemical compound from the Indexes to the abstracts issued by the Chemical Society or the Society of Chemical Industry, one would require to scan the Indexes not only under the name of the present compound but also under all the possible variations in arrangement of parts of the name, and this without systematic guidance from the Index itself.

Such circumstances have induced a preliminary study of indexing practice of British Chemical Abstracts, the Chemische Zentralblatt, and Chemical Abstracts. In this study, the results of which are here presented, the comprehensiveness with which the literature is covered, questions of cost or other points of economics, interval between the appearance of the original paper and the abstract, and the qualifications of indexing staff, have not been considered. The prime purpose has been a comparison of the three systems in practice in regard to the indexing of chemical compounds, and, as a sample, the indexing of some typical compounds, namely, butadiene, the butylene glycols and ethylene glycol over the last fifty years was examined.

\section{Ethylene Glycol}

Chemische Zentralblatt. In the Index to the 1897 volume this compound is entered under "Glykol". "Athylen Glykol" appears in the Collective Index for 1897-1901, but there is no cross-reference to or from "Glykol". A similar remark applies to the 1899 Index. In the 1900 Index, "Glykol" is used as a generic term. Separate entries appear under both names in the 1901 Index, while from 1905 onwards entries under "Glykol" are differentiated by formulæ. In 1906 and subsequent Indexes there is a crossreference from "Glykol" to "Äthylen Glykol", but the Collective Indexes 1897-1921 contain entries under "Äthylenglykol" with a cross-reference "Glykol see Athylenglykol". In the 1922-24 Collective Index this practice is reversed. Entries are placed under "Glykol (Äthylenglykol)" with an entry "ÄthylenglykolSee Glykol", and in the 1925-29 Index the entries under "Glykol" are classified in the usual manner under "preparation, physical properties, chemical properties". Thereafter entries are consistently placed under "Glykol" with cross-reference "Äthylenglykol-See Glykol".

British Chemical Abstracts. The Indexes to the Chemical Society's Abstracts for 1897 and 1898 contain the entry "Ethylenic Glycol", and in 1899 there is the cross-reference "Glycol, see Ethylenic Glycol". During 1900-13 this becomes "Glycol. See Ethylene Glycol", and entries are placed under "Ethylene glycol". The latter term is the sole entry in the Indexes for 1915-17 and 1920-26, but in 1918 and 1919 the cross-reference "Glycol. See Ethylene glycol" is again given, and also in the Collective Indexes, 1903-12, 1913-22, 1923-32 and 1933-37 and the Annual Indexes to British Chemical Abstracts from 1927 onwards, with the exception of those for the years 1934-36 and 1943-44, when the crossreference from "Glycol" is dropped although the entries are still placed under "Ethylene glycol".

Chemical Abstracts. In the Indexes to the 1907-9 volumes there are entries under "Ethylene glycol" and "Glycol" with no cross-reference. In 1910 there are entries under "I : 2-Glycol" but none under "Ethylene glycol". In 1911 "Glycol" only is entered, and in the following year both "Ethylene glycol" and "Glycol" appear without cross-reference : the entries under "Glycol" in this year (1912) relate to derivatives. Entries in 1913 and 1914 are similar, but in 1915 under "Glycol" there is entered "See also Ethylene Glycol". In 1918 under "Glycol" is entered the note: "Individual glycols not having a common name, e.g., glycol, are indexed under the Geneva name, e.g., Propanediol". This note is repeated in 1919 and afterwards. The same volumes contain the entry "Ethylene glycol. See Glycol. For derivatives see 1 : 2-Ethanediol, 1 : 2-Propanediol, etc.", and this is repeated at intervals down to 1944.

\section{Butylene Glycol}

The indexing of butylene glycol in the period 1901-44 presents a similar picture. In the Chemische Zentralblatt, entries are made both under "Butylen glykol" and "Butandiol", and only in 1919 is there a cross-reference "See Butylen glykol" under "Butandiol". But from 1922 onwards entries under 
"Butandiols" and "Butylen glykols" are transferred to the Formula Index.

In British Chemical Abstracts and Chemical Abstracts, entries are made both under "Butylene glycol" and "Butane diol", frequently without crossreference; and although the tendency in Chemical Abstracts from 1918 onwards is to enter under "Butane diol" in accordance with the note already quoted under "Ethylene glycol"-_"Individual glycols not having a common name, e.g., glycol, are indexed under the Geneva name, e.g., Propanediol"'-the Index to the volume for 1920 contains the entry "Butane diol. See Butylene glycol".

\section{Butadiene}

Chemische Zentralblatt. "Butadiene" first appears under that name in the 1897-1901 Collective Index. The Index to the volume for 1903 contains an entry under "Erythren" but nothing under "Butadiene". In the 1902-6 Collective Index all three names, "Butadiene", "Erythren" and "Divinyl", are entered, but there are no cross-references. There is a reference under "Erythren. See Divinyl" in the 1911 Index, but "Butadiene" is entered separately with no crossreference. In the index to the second volume for the same year, "Butadiene" and "Erythren" are entered separately with no crossi-reference or to "Divinyl". In 1912 there is an entry under "Erythren" and a cross-reference "Butadiene. See Erythren". In 1913 "Divinyl" and "Erythren" are entered separately for the first half-year, and in the second half-year there are entries "Butadiene" and "Erythren" but with no entry for "Divinyl". The Indexes for 1914 and 1915 contain entries for "Butadiene" and "Erythren" but no cross-reference; and in 1916 there are entries under "Divinyl" and "Erythren" but not under "Butadiene", and there are no cross-references. Similarly, the entries in 1918 under "Divinyl" and "Butadiene" are without cross-references; and also in 1919 under "Butadiene" and "Erythren" and in 1921 under "Butadiene". The 1912-15 Collective Index refers from "Butadiene" to "Erythren" and vice versa, but there is no reference from either to "Divinyl", which is entered without a cross-reference. In the 1917-21 Collective Index, "Divinyl" and "Erythren" are both entered without cross-reference and there is no entry under "Butadiene". In the following Collective Index (1922-24) there are entries "Erythren. See $\mathrm{C}_{4} \mathrm{H}_{6}$ ", "Butadiene. See $\mathrm{C}_{4} \mathrm{H}_{6}$ ", but there is no entry under "Divinyl". In the next Collective Index (1925-29) all three names are referred to the Formula Index.

British Chemical Abstracts. Much the same variations are found in the Abstracts of the Chemical Society and in British Chemical Abstracts. In 1899 the entry "Divinyl. See Butinene" occurs, while "Butinene (Divinyl)" is also entered. In 1901 the following entries are made:

"Butinene (Ethylacetylene),

Butinene (Crotonylene, dimethylacetylene)";

but there is none under "Butadiene", "Divinyl" or "Erythrene". "Butadiene" appears in 1904, and in 1905 in addition to "Butadiene" and "Erythrene" there is the entry "Butinene. See Erythrene". "Butadiene" alone is entered in 1906, " $\Delta^{u \gamma}$-Butadiene" in 1907, "n-Butinene" in 1909, and "Butadiene" and "Erythrene" in 1912. In 1913 there are the following entries: "Erythrene", " $\Delta^{a \gamma}$-Butadiene", " $\Delta^{\alpha}$-Butinene", " $\Delta^{\beta}$-Butinene. See Crotonylene", In 1914 there are entries for
"Butadienes", " $\Delta^{a \gamma}$-Butadiene", " $\Delta^{a}$-Butinene" and "Erythrene" but no cross-references; in 1915 "Butadiene"; in 1916 "Divinyl" and "Erythrene" (without cross-reference); in 1917 "Divinyl"; and in 1923 "Butadienes" only. In 1924 "Butadiene", and " $\Delta \gamma$-Butinene $\mathrm{CH}_{2}$ : CH.CH : $\mathrm{CH}_{2}$ " are entered, while the Collective Index 1923-32 gives "Butadiene", " $\Delta^{a \beta}$-Butadiene", " $\Delta^{\alpha \gamma}$-Butadiene", "Butadienes", "Erythrene (See also Hydrocarbons, erythrene)", "Divinyl"; but without other cross-references. The Collective Indexes, 1903-12 and 1913-22, similarly give all three terms without cross-references. Similar inconsistencies persist in the annual indexes down to 1940. Some years one term is used and in others another, with no cross-reference in either volume. For example, in 1926, both "Butadiene" and "Erythrene" appear ; in 1930 "Butadiene" and "Divinyl"; while in 1934 all three are entered. "Divinyl" appears again in 1937 and 1938, but not afterwards. "Erythrene" is only entered again in 1939 and thereafter entries are under "Butadiene" or " $\Delta^{\alpha \gamma}$-Butadiene", but without cross-references.

Chemical Abstracts. "Butadiene" first appears in the Index to Chemical Abstracts in 1911, and in 1912 "Butadiene", "Divinyl" and "Erythrene" are all entered. In 1913 "Butadiene" and "Erythrene" are entered; all three appear in 1914 and 1915 ; but not until 1916 are there cross-references, when "Divinyl" is made the main entry and "Erythrene" and "Butadiene" are entered with the note "See Divinyl".

This practice, however, was not adhered to rigorously, for in 1918 there are entries under "Butadiene" but not under "Erythrene" or "Divinyl", and the entry "Bivinyl" and the cross-reference "Butadiene. See Bivinyl" do not appear until 1921. In 1922 "Butadiene" and "Divinyl" are entered, but not "Bivinyl" or "Erythrene". In 1923 "Butadiene. See Bivinyl" is again entered, but the only entry under "Erythrene" is "Erythrene, $\alpha \alpha$-dimethyl-See 1 : 3-Pentadiene, 4-methyl-". In 1925 there is the entry : "Bivinyl (erythrene) (for derivatives, see under 1 : 3-butadiene, etc.)" and also "Erythrene, see Bivinyl", both of which are repeated in 1926 . The entry "Divinyl, see Bivinyl" is not repeated in 1926, although this volume includes the entry "1 : 3-Butadiene, see Bivinyl".

The indexing appears to become more systematic from 1927 onwards, though the editors appear to be unable to make up their minds which name to adopt as the main entry. Thus in 1927 we find " $1: 3$ Butadiene, see Bivinyl"; "Erythrene, see Bivinyl"; "Bivinyl (Erythrene). For derivatives see under 1 : 3-Butadiene, etc.", and in 1928 "Divinyl, see Bivinyl". In 1931, however, there are no entries under "Divinyl" and "Erythrene", and under "Bivinyl" is entered "see 1 : 3-Butadiene". There are no cross-references from "Butadiene". Again, although in 1934 and 1935 "Bivinyl" is entered "see Butadiene", and "Butadiene (bivinyl)", there are no entries or cross-references for "Divinyl" and "Erythrene". In 1937 there is entered "Bivinyl (Erythrene), see also Butadiene"; "1 : 3-Butadiene, see also Bivinyl"'; "Divinyl, see Bivinyl"; "Erythrene, see Bivinyl". In 1938 "Bivinyl" is entered "see 1:3-Butadiene"; but although bivinyl is given in brackets after "Butadiene", there are no entries under erythrene or divinyl. In 1941 "Butadiene" is entered "See also Di- under Olefins" and "Olefins, di-", "See also Rubber substitute and synthetic". In 1942-44 butadiene is entered "Butadiene (Bivinyl). 
See also Rubber substitute and synthetic" and in "Di-" under "Olefins".

These examples indicate that while cross-referencing in the indexes to Chemical Abstracts is no more systematic than in British Chemical Abstracts, it is somewhat more complete. What is more impressive, however, when the indexes are compared, is the extent to which the editors of Chemical Abstracts have from the start attempted to define precisely the indexing policy followed and to modify this from time to time to incorporate any practice on which some general international agreement has been reached. For example, in 1938 40 the nomenclature and indexing for inorganic compounds was modified in accordance with the recommendations of the report of the German Commission (Helv. Chim. Acta, $20,159 ; 1937)$ and the rules of the Commission on the Reform of the Nomenclature of Inorganic Compounds (Ber., 73A, 53; 1940; J. Chem. Soc., 1404; 1940); while in 1935 Crane's modified Broughton system was brought into use for deuterium compounds (Ind. Eng. Chem., News Ed., 13, 200 ; 1935). In the 1938 Index the practice used in botanical and zoological nomenclature is also defined, and the authorities used for insects, for bacteria, and for alloys are specified.

The practice followed in indexing organic compounds is described in detail in prefaces to the indexes to successive volumes, notably in those for $1917,1927,1937$ and 1945, and the Collective Indexes for 1907-16 and 1917-26. The basis of this has been the system of organic chemical nomenclature described by A. M. Patterson and C. E. Curran (J. Amer. Chem. Soc., 19, 1623; 1917), and the most striking change in the indexing methods is the inversion of all names containing substituent prefixes, "Chloroacetic acid", for example, being now placed under "Acetic acid, chloro-". This is in keeping with the principle laid down in the preface to the 1918 volume that subjects, not words, are indexed; but the idea of arranging alphabetically on the basis of the parent compound was taken from the Journal of the Chemical Society, although it was not until the 1923-32 Collective Index that the practice was systematically adopted in British Chemical Abstracts. Afterwards, in 1937, some changes were made towards the adoption of the Rules given in the Definitive Report of the International Committee on Organic Nomenclature (J. Chem. Soc., 1607; 1931 ; J.Amer. Chem. Soc., 55, 3905 ; 1933; ef. also C. Smith, J. Chem. Soc., 1067 ; 1936). Although there is nothing to indicate the fact in prefaces to Chemical Abstracts or British Chemical Abstracts, according to a paper by E. J. Crane (J. Chem. Educ., 8, 1335; 1931) in 1923 the Nomenclature Committee of the Chemical Society, London, and that of the American Chemical Society, agreed on the rules covering some of the more commonly disputed points, including some of significance for classification.

In contrast to this it is difficult to trace definite evidence that any of these reports on organic or inorganic nomenclature or on the nomenclature of deuterium compounds have been adopted in British practice. Apart from a brief preface to the Collective Indexes for 1883 and 1892, according to which the index is in the main alphabetical, but wherever practicable substances are arranged alphabetically and under such well-defined main groups as alkaloids, carbohydrates, glucosides, etc., there is no further preface or explanatory note until the Collective Index for 1923-32, when the practice already noted of placing certain substituent groups after the remainder of the name is adopted. Some indication as to indexing practice may be found in the "Instructions to Abstractors" which are sometimes to be found bound with the Abstracts, although I have not been able to trace an issue earlier than 1918. Much of this, and indeed the use as standard of reference of the Collective Indexes of the Chemical Society, 191322 and 1923-32, involves the translation of names used in American and other chemical periodicals, to fit rather a set of rules than a defined system or set of principles.

From this preliminary survey certain tentative conclusions can be drawn.

(1) Chemical Abstracts represents the most persistent attempt to provide adequate alphabetical indexing of chemical compounds by name; but even in current practice, room for considerable improvement can be seen.

(2) Both in Chemical Abstracts and in Chemische Zentralblatt there can be seen a distinct trend towards a formula index for indexing definite organic chemical compounds, in view of variations in chemical nomenclature and to allow for compounds not named by their originators.

(3) There is some evidence of a trend towards agreement on nomenclature between the British and American Chemical Societies, but progress in this direction is unlikely to be rapid and the general adoption of an international system by all chemists is a remote probability, even disregarding the fundamental difference of mother tongues.

(4) Independently of the question of coverage and of the economic aspects of abstracting, on the basis of circulation and resources, it is now improbable that British Chemical Abstracts could ever hope to compete with Chemical Abstracts; nor has this survey revealed any reason for making the attempt.

(5) The law of scattering deduced by the late $\mathrm{Mr}$. E. Lancaster-Jones in an investigation instigated by Dr. S. C. Bradford (cf. Engineering, 137, 85 ; 1934; also Rep. Proc. 14th Conf. Assoc. Spec. Lib. and Inform. Bur., 1937, pp. 59-71 ; and F'.I.D. Comm., 13,61-65 1946) suggests that the best means of securing complete cover is not by rival abstracting organisations, but by functional co-operation and laying out the field by sciences on some such basis as the Universal Decimal Classification.

The most important development to be desired appears to be the standardization of indexing practice, probably on the basis of formulæ rather than names, and the establishment of some central body with adequate resources to provide comprehensive annual and decennial, or other periodic indexes, as may be most convenient, for English-speaking chemists. Since reports from Germany (cf. Ind. Eng. Chem., News Ed., 24, 790 ; 1946) suggest that the future of the Chemische Zentralblatt is highly uncertain, this appears to be the most urgent need and much more essential than the question of abstracting. If any financial resources can be set free for the purpose by elimination of redundant abstracting, that might strengthen the case for Government assistance if required. Since, however, the provision of such comprehensive indexes would be of great assistance to industrial research in particular, it should not be difficult to make out a strong case in the first instance for support by industry as well as by the State. 